San Jose State University

SJSU ScholarWorks

Faculty Publications, Chemistry

Chemistry

$1-1-2002$

\title{
Chemical analysis by X-ray spectroscopy near phase transitions in the solid state
}

Juana Vivó Acrivos

San Jose State University, juana.acrivos@sjsu.edu

L. Nguyen

San José State University

T. Norman

San José State University

C. T. Lin

IRC for Superconductivity, Cavendish Laboratory, Cambridge CB3 OHE UK

W. Y. Liang

IRC for Superconductivity, Cavendish Laboratory, Cambridge CB3 OHE UK

See next page for additional authors

Follow this and additional works at: https://scholarworks.sjsu.edu/chem_pub

Part of the Physical Chemistry Commons

\section{Recommended Citation}

Juana Vivó Acrivos, L. Nguyen, T. Norman, C. T. Lin, W. Y. Liang, J. M. Honig, and P Somasundaran. "Chemical analysis by X-ray spectroscopy near phase transitions in the solid state" Microchemical Journal (2002): 117-131. https://doi.org/10.1016/S0026-265X(02)00004-8

This Article is brought to you for free and open access by the Chemistry at SJSU ScholarWorks. It has been accepted for inclusion in Faculty Publications, Chemistry by an authorized administrator of SJSU ScholarWorks. For more information, please contact scholarworks@sjsu.edu. 
Authors

Juana Vivó Acrivos, L. Nguyen, T. Norman, C. T. Lin, W. Y. Liang, J. M. Honig, and P Somasundaran 
Chemical analysis by X-Ray spectroscopy near phase transitions in the solid state

Juana Vivó Acrivos*, L. Nguyen and T. Norman

San José State University, San José CA95192-0101

C.T. Lin and W.Y. Liang

IRC for Superconductivity, Cavendish Laboratory, Cambridge CB3 OHE UK

J.M. Honig, P. Somasundaran

Purdue University, Lafayette IN 47907-1393 


\begin{abstract}
The methods discussed in this work show that the types of changes which may be observed, by precise XAS measurements of Absorbance A versus temperature, across a phase transition are: the changes in the relaxation time of the final states $t$ due to fluctuations near a phase transition; the detection of the anomalous Bragg condition coupled to phonon modes XAS enhancement that identifies the temperature interval where the phonon modes are active, the symmetry changes which introduce new allowed transitions to finite states below an element edge, near $T_{c}$ indicate what symmetry changes occur, and the method of $\mathrm{XTDAFS}_{\mathrm{T} 0}=\mathrm{XAFS}(\mathrm{T})-\mathrm{XAFS}\left(\mathrm{T}_{0}\right)$, allows the precise measurement of the progressive changes in the Debye-Waller factor versus $\mathrm{T}$ near a phase transition, and identify (when no other structural changes occur, except in the vibrational modes of a specific bond) the bond responsible for the transition. The methods have been applied to the superconducting transition in layer cuprates and the metal to insulator transition in $\mathrm{NiS}_{2-\mathrm{x}} \mathrm{Se}_{\mathrm{x}}$.
\end{abstract}

* Telephone: 1408924 4972; fax: 14089244945

* email: jacrivos@athens.sjsu.edu

Keywords: phase transitions, superconductivity, antiferromagnetism, X-ray absorption spectroscopy 


\section{Outline}

1. Introduction to chemical analysis of Solids by X-Ray absorption spectroscopy

2. Experimental:

2.1 Instrumentation details for XAS

\subsubsection{Optical density measurements}

2.1.2 Calibration procedures

2.2 Applications to solid state phase transitions

\subsubsection{Materials}

2.2.2 Temperature control

\subsubsection{Precision}

3. Discussion

\subsection{Electromagnetic relations}

3.2 Phase transitions

3.3 Phenomena observed at phase transitions

4. Conclusions

4.1 Use of techniques

4.2 Phenomena

5. Acknowledgements

6. References

7. List of figures

8. Figures 


\section{Introduction}

Continued innovation in synchrotron radiation facilities (up to $3^{\text {rd }}$ generation at present) have provided improvements that allow new types of measurements in the study of solid state phase transitions using X-ray absorption spectroscopy (XAS) that were not possible up to date. This review article addresses the feasibility of accurate measurements that determine what changes occur in the valence, the bond order and the structure of materials undergoing phase transitions. This type of chemical analysis is important for the design of new materials with desired properties for applications in the solid state industry. This work describes the instrumental calibration, and stability required for accurate measurements, and the supporting theory that can give information on new phenomena. Examples of the different phenomena observed in different types of phase transitions will show the power of the method.

The phase transitions in solids are driven by a large variety of electronic processes that in turn lead to structural changes. A material may exhibit different phases, e.g. [1],

Metal / Insulator / Superconductor / Antiferromagnetic / Ferromagnetic / etc., (1) according to the ambient temperature $\mathrm{T}$, pressure $\mathrm{P}$, and free electron concentration.

\section{Experimental}

\subsection{Instrumentation details}


All syncrotron facilities supply photons with varying degrees of monochromaticity. Figure 1 gives the diagram of a spectrometer used at the Stanford Synchrotron Radiation Laboratory (ssrl) for the work reported here.

\subsubsection{Optical density measurements}

The optical density is determined from the current $\mathrm{I}_{\mathrm{i}}$ measured at different ionization chambers that constitute the spectrometer in Figure 1, where the sub index i identifies what the ionization chamber measures: 0 , the incident radiation; 1 , the radiation transmitted by the sample; and 2, the radiation transmitted by the reference material. The textbook [2] definition of Absorbance at given frequency $v$ :

$$
\mathrm{A}_{v}=-\log _{10} \mathrm{~T}_{r v}
$$

is determined from the Transmittance of the sample $\mathrm{T}_{r v}=\mathrm{I}_{1 v} / \mathrm{I}_{0 v}$ at the frequency $v$. The $\mathrm{X}$-ray energies $\mathrm{h} v$ are determined by the angle $\Theta$ that white synchrotron radiation makes with the diffraction planes (hkl) of two parallel Si crystals in the monochromator. The possibility of higher harmonics, nhv is always present because of allowed diffractions n(hkl). The higher harmonics can be eliminated because their rocking curves are sharper than for the fundamental, but these must be eliminated by calibration procedures in every experiment in order to eliminate uncertainties.

\subsubsection{Calibration procedures}

The frequency is selected by diffraction, and a fraction $\mathrm{x}$ of higher harmonics $\mathrm{n} v$ ( $\mathrm{n} \geq 2$ ) present in the beam must be ascertained. If $\mathrm{I}_{0}$ and $\mathrm{I}_{1}$ are the currents measured at 
the respective ionization chambers, and $\mathrm{x}$ is the fraction of higher harmonics in the incident beam and $x^{\prime}$ is that in the transmitted beam then:

$$
\begin{gathered}
\mathrm{I}_{0, v}=(1-\mathrm{x}) \mathrm{I}_{0}, \quad \sum_{\mathrm{n} \neq 1} \mathrm{I}_{0, \mathrm{n} v}=\mathrm{x} \mathrm{I}_{0}, \\
\mathrm{I}_{1, v}=\left(1-\mathrm{x}^{\prime}\right) \mathrm{I}_{1}, \quad \sum_{\mathrm{n} \neq 1} \mathrm{I}_{1, \mathrm{nv}}=\mathrm{x}^{\prime} \mathrm{I}_{1}, \\
\mathrm{x}^{\prime} /\left(1-\mathrm{x}^{\prime}\right)=\mathrm{x} 10^{\mathrm{A}_{v}} /(1-\mathrm{x}) .
\end{gathered}
$$

The measured Absorbance $A=\log _{10}\left(\mathrm{I}_{0} / \mathrm{I}_{1}\right)$ approaches $\mathrm{A}_{v}$ only as $\mathrm{x}$ approaches zero, i.e.,

$$
\begin{gathered}
\mathrm{A}_{v}-\mathrm{A}=\log _{10}\left((1-\mathrm{x}) /\left(1-\mathrm{x}^{\prime}\right)\right)=\log _{10}\left(1+\mathrm{x}\left(10^{\mathrm{A}_{v}}-1\right)\right) \\
->\mathrm{x}\left(10^{\mathrm{A}_{v}}-1\right) / \operatorname{Ln}(10) \geq 0, \text { as } \mathrm{x}->0 .
\end{gathered}
$$

Since a monochromatic beam is essential for accurate measurements, it is achieved by detuning the second Si crystal in the monochromator from the exact diffraction angle by $\Delta \Theta$ with a piezoelectric device (Figure 1). Negligible harmonic content is usually obtained by an $80 \%$ detuning of $\mathrm{I}_{0}$ [3]. The higher harmonics $\mathrm{n} v$ are eliminated because they are narrower than the fundamental diffraction, which is then shifted by the amount $\Delta \mathrm{E}=\mathrm{E} \cot \Theta \Delta \Theta[4 \mathrm{a}]$. Attention to these calibration details must be done to achieve the desired accuracy. The monochromaticity of the beam is determined in the limit of $A_{v} / A=$ 1 (Figure 2a,b). At $80 \%$ detuning, $\mathrm{x} \rightarrow 0$, and a $4 \mathrm{eV}$ shift is observed at the $\mathrm{Cu}_{\mathrm{K}}$ edge with a (111) Si cut crystal. The reason for this is that the detuning shifts the energy to where the sharper higher harmonic [Figure 5 of ref. 4] practically disappears, but the principal harmonic still has $20 \%$ intensity. By measuring the intensities of the fundamental and the higher harmonics, Latimer et al. [3] have confirmed that $80 \%$ detuning indeed produces a monochromatic beam of very high $v$ monochromaticity. Throughout an experiment the stability of $A_{v 2}$ and $E_{02}$ for the reference compound (measured by $I_{2}$ in the spectrometer shown in Figure 1) is used to determine the limits of 
accuracy. The rejection of the higher harmonics depends on the edge being measured and must be done for every experiment. The raw data for the sample versus temperature $\mathrm{T}$ can only be analyzed after the reference (kept at room temperature) shows the desired stability obtained with an $\mathrm{I}_{0}$ detuning of $80 \%$ (Figure 2c). Fluorescence measurements can not be checked for accuracy with $\mathrm{I}_{2}$.

The temperature is monitored with an Oxford 9000 cryogenic system and recorded digitally with Oxford Object Bench PC software. Typical measurements are carried out in complete temperature cycles (insert, Figure 2c).

\subsection{Applications to solid state phase transitions}

\subsubsection{Materials}

The methods have been applied to materials that are metals and insulators, cubic materials and low dimensional solids (LDS). These vary from superconductors, antiferromagnetic and ferromagnetic insulating and conducting materials: $\mathrm{YBa}_{2} \mathrm{Cu}_{3} \mathrm{O}_{7-\delta}$ single crystal prepared at IRC for Superconductivity [5], $\mathrm{Nd}\left(\mathrm{Ba}_{0.95} \mathrm{Nd}_{0.05}\right)_{2} \mathrm{Cu}_{3} \mathrm{O}_{7}$ powders

prepared at Morris Laboratories [6] and $\mathrm{NiS}_{2-\mathrm{x}} \mathrm{Se}_{\mathrm{x}}$ prepared at Purdue University [7]. A typical sample mount that goes inside the cryostat (Figure 1) is shown in Figure 3, together with the $\mathrm{YBa}_{2} \mathrm{Cu}_{3} \mathrm{O}_{7-\delta}$ single crystal orientation used in this work.

\subsubsection{Temperature Control}

The data is acquired in temperature cycles. The reproducibility of the reference spectra in a given temperature cycle is very important. Reproducibility must be verified (Figure 2c) [8]. 


\subsubsection{Precision}

Once the data is obtained to a given precision, the analysis is carried out by measuring the following parameters: the X-ray absorption for excitations to bound states near an element edge, XANES; the edge energies, $\mathrm{E}_{0}$; the X-ray absorption fine structure, XAFS and the X-ray temperature difference absorption spectra XTDAS [9]:

$$
\mathrm{XTDAS}_{\mathrm{T} 0}=\mathrm{A}_{v}(\mathrm{~T})-\mathrm{A}_{v}\left(\mathrm{~T}_{0}\right)
$$

is used to ascertain the changes in XAS relative to a temperature $\mathrm{T}_{0}$ which may be near or above the phase transition temperature. New phenomena are determined as follows:

2.2.3.1 Changes in bond distance are determined by XAFS analysis [10].

2.2.3.2 Changes in bond order are determined by the so called atomic XAFS, (AT)AXAFS [11]. Here the X-ray fine structure changes due to a variation of the bond order. Electron density changes at distances less than an Ångstrom from the heavy absorbing heavy atom [11] are observed near the phase transition by XTDAS [12].

2.2.3.3 Changes in oxidation states are determined by precise measurements of edge shifts, to the accuracy given by the reference edge measurements [4].

2.2.3.4 Changes in the XANES may also occur if there are changes in the symmetry and the density of final states $N\left(E_{E}\right)$ near a phase transition $[9,10,12]$.

\section{Discussion}

\subsection{Electromagnetic radiation relations for XAS}

A basic knowledge of the electromagnetic theory [2] involved in XAS is necessary for the interpretation of data. The excitation of electrons in core states to states 
in a continuum of high kinetic energy probe the local potential for the absorber $A$. The angular dependence of the X-ray absorption cross section $\sigma(\omega)$ [13] for a particle at $\mathbf{r}$, of mass $\mathrm{m}_{\mathrm{e}}$, charge $\mathrm{q}$, and spin s gyromagnetic ratio g, moving in a static potential $\mathrm{V}(\mathbf{r})$ and under the influence of the electromagnetic radiation fields $(\Phi, \mathbf{A})$ at a frequency $\omega=2 v \pi$, crossing the unit area, normal to the propagation direction, at the rate $I(\omega)=2 \varepsilon_{0} \mathrm{c}\left|\mathbf{A}_{0}\right|^{2} \omega^{2}$ is obtained from the Hamiltonian:

$$
\mathbf{H}=\mathbf{H}_{0}+\left[i \mathrm{q} \mathrm{h} / 2 \pi \mathrm{m}_{\mathrm{e}} \mathbf{A} \cdot \boldsymbol{\nabla}+\boldsymbol{h} \boldsymbol{c}\right]+\mathrm{q}^{2} / 2 \mathrm{~m}_{\mathrm{e}} \mathbf{A}^{2}+\mathrm{q} \Phi-\left(\mathrm{g} \mathrm{q} / 2 \mathrm{~m}_{\mathbf{e}}\right) \mathbf{s} \cdot \mathbf{B},
$$

where

$$
\mathbf{H}_{0}=-(\mathrm{h} / 2 \pi)^{2} \nabla^{2}+\mathrm{V}(\mathbf{r}), \mathbf{A}(\mathbf{r}, \mathrm{t}),=\mathbf{A}_{0} \hat{\mathbf{e}} \mathrm{e}^{i(\mathbf{k} . \mathbf{r}-\omega \mathrm{t})}+h c,
$$

$h c$ is the Hermitiean conjugate, $\varepsilon_{0}$ is the permittivity of vacuum, c is the velocity of light, $\hat{\mathbf{e}}$ is the unit polarization vector, $\mathbf{k}$ is the $\mathrm{x}$-ray wave vector, and $2^{1 / 2} \mathbf{A}_{0}$ is the vector potential amplitude. A perturbation W:

$$
\mathrm{W}(\mathrm{t})=\mathrm{W} \mathrm{e}^{-\mathrm{i} \omega \mathrm{t}}+h c
$$

gives a transition probability w per unit time:

$$
\mathrm{W}=4 \pi^{2} / \mathrm{h} \Sigma_{\mathrm{f}}|<\mathrm{f}| \mathrm{W}|\mathrm{i}>|^{2} \delta\left(\mathrm{E}_{\mathrm{f}}-\mathrm{E}_{\mathrm{i}}-\mathrm{h} v\right) .
$$

If the perturbation consists of a plane wave satisfying the relation for the magnetic induction $\mathbf{B}=\nabla \mathbf{x} \mathbf{A}$, the transition probability simplifies to:

$$
\mathrm{w}=\left(4 \pi^{2} \mathrm{q}^{2} / \mathrm{hm}_{\mathrm{e}}{ }^{2}\right)\left|\mathbf{A}_{0}\right|^{2} \Sigma_{\mathrm{f}}|<\mathrm{f}| \mathrm{e}^{i(\mathbf{k} . \mathbf{r}-\omega \mathrm{t})}\{\hat{\mathbf{e}} . \nabla \mathrm{h} / 2 \pi-(\mathrm{g} / 2) \mathbf{s}(\square \mathbf{k} \mathbf{x} \hat{\mathbf{e}})\}|\mathrm{i}>|^{2} \delta\left(\mathrm{E}_{\mathrm{f}}-\mathrm{E}_{\mathrm{i}}-\mathrm{h} v\right),
$$

and, the absorption cross section defined as:

$$
\sigma(\omega)=(\mathrm{wh} v) / \mathrm{I}(\omega)
$$

is written, in the absence of magnetic interactions [13] in a series expansion: 


$$
\sigma(\omega)=2 \pi \alpha h \omega \Sigma g_{i, f}\left\{|<f| \mathbf{e} . r|i>|^{2}+0.25|<f| \hat{e} . \mathbf{r} \text { k.r. }|i>|^{2}+. .\right\} \delta\left(E_{f}-E_{i}-h v\right) .
$$

(6.1)The important spectroscopic applications are derived from relation (6.1). The first and second terms in the expansion may be detected with highly polarized synchrotron radiation, giving rise to the dipolar and quadrupolar terms. Thus, one may detect any symmetry changes near a phase transition. The absorption cross section has several contributions:

3.1.1 The atomic (AT)XAS cross section $\mathrm{K}_{A}$ versus energy, $\mathrm{E}=\mathrm{h} v$ in the neighborhood of an X-ray edge $\left(\mathrm{E}_{0}=\mathrm{h} v_{0}\right)$ for the absorber $A$, is given by the sum of Lorentzian curves [14].

$$
\begin{gathered}
\mathrm{K}_{A}\left(\tau,\left(v-v_{0}\right)\right)=\Sigma_{\mathrm{AE}} \mathrm{a}_{A} /\left[1+(2 \pi \tau)^{2}\left(v_{A E}-v\right)^{2}\right] \\
\rightarrow \int_{0}^{\mathrm{E}-\mathrm{E} 0} \mathrm{~N}\left(\mathrm{E}_{\mathrm{E}}\right) /\left[1+(\mathrm{m} \mathrm{x})^{2}\right]=\mathrm{C}_{A}\left\{\pi / 2+\operatorname{atan}\left(2 \pi \tau\left(v-v_{0}\right)\right\},\right.
\end{gathered}
$$

where $\mathrm{a}_{A}$ and $\mathrm{C}_{A}$ are constants determined by the material and $\mathrm{h} v_{A E}$ is the excitation energy (Figure 4), the photoelectron wave vector is

$$
k\left(\AA^{-1}\right)=\left(0.2625\left(E-E_{0}\right)\right)^{1 / 2}
$$

when $\mathrm{E}$ is in $\mathrm{eV}$, the initial and final states energies are $\mathrm{E}_{\mathrm{A}}$ and $\mathrm{E}_{\mathrm{E}}$ respectively,

$$
\begin{gathered}
\tau=6.5821 * 10^{-16} \mathrm{~s} / \mathrm{HWHH}, \\
\mathrm{E}_{\mathrm{AE}}=\mathrm{E}_{E}-\mathrm{E}_{\mathrm{A}}=\mathrm{h} v_{\mathrm{AE}}, \\
\mathrm{x}=\mathrm{E}-\mathrm{E}_{\mathrm{AE}}, \\
\mathrm{m}=2 \pi \tau / \mathrm{h},
\end{gathered}
$$

HWHH is the half line width at half height in $\mathrm{eV}$, and the final density of states $\mathrm{N}\left(\mathrm{E}_{\mathrm{E}}\right)$ is determined by the states in the material.

The local potential $\mathrm{V}(\mathbf{r})$ determines the states' lifetime. In the absence of fluctuations: 


$$
1 / \tau=1 / \tau_{\text {if }}=\left(1 / \tau_{\text {initial states }}+1 / \tau_{\text {final states }}\right) / 2 \text {. }
$$

For energies below an edge (near 5 to $13 \mathrm{keV}$ ) the natural relaxation times are determined from the magnitude of the half line widths $(0.5$ to $1 \mathrm{eV})$ to be $\tau_{\mathrm{if}} \geq 10^{-16} \mathrm{~s}$.

3.1.2 The analysis of multiple the transitions which occur immediately above the edge is complicated, but $50 \mathrm{eV}$ above the edge the $\mathrm{X}$-ray absorption fine structure (XAFS) modulates $K_{A}$, and is manipulated for structure analysis $[9,10,14 \mathrm{f}]$ which is not included in this work: The photoelectron emitted by $A$ travels to a neighboring atom $B$ at a bond distance $\mathrm{R}_{A B} \sim 3 \AA$ and back in less than $10^{-17} \mathrm{~s}$. In the absence of fluctuations the measured relaxation time is $\tau=\tau_{\text {if. }}$ In the presence of fluctuations in the potential, which limits the lifetime of the final state, the line width obtains:

$$
1 / \tau=1 / \tau_{\text {if }}+1 / \tau_{\text {fluctuations }} .
$$

Thus, XAS is ideally suited to measure changes in the relaxation times of the order $10^{-16}$ to $10^{-17} \mathrm{~s}$ near a phase transition.

3.1.3 At room temperature, the transitions to states below the edge, XANES obey the symmetry selection rules, and the line widths give the natural lifetime of the final states of $10^{-16} \mathrm{~s}^{11}$. Any decrease in $\tau$ below $10^{-16} \mathrm{~s}$ can be detected by its effect on the atomic absorption coefficient $\mathrm{K}_{A}$. Then the calculated absorption coefficient for atomic (AT)XAS, $\mathrm{K}_{\mathrm{A}}\left(\mathrm{m}, \mathrm{E}-\mathrm{E}_{0}\right)$ and its variance versus $\mathrm{m}=2 \pi \tau / \mathrm{h}$, and $\mathrm{E}-\mathrm{E}_{0}$ (Figure 4a-d), are used to ascertain the value $\tau$ from the data (Figure 5a), i.e.,

$$
\begin{gathered}
\mathrm{m}(\mathrm{T}) / \mathrm{m}\left(\mathrm{T}_{\mathrm{c}}\right)=\tau(\mathrm{T}) / \tau\left(\mathrm{T}_{\mathrm{c}}\right)= \\
\left(1 / 10^{-16} \mathrm{~s}+1 / \tau_{\text {fluctuations }}\left(\mathrm{T}_{\mathrm{c}}\right)\right) /\left(1 / 10^{-16} \mathrm{~s}+1 / \tau_{\text {fluctuations }}(\mathrm{T})\right) \\
\rightarrow \tau(\mathrm{T}) / \tau_{\text {fluctuations }}\left(\mathrm{T}_{\mathrm{c}}\right)
\end{gathered}
$$


Once the correct accuracy is achieved, the XAFS, XTDAS, (AT)XAS and (AT)XAFS are analyzed by computer programs developed during the last ten years in the literature [14]. Only then can the phenomena that occur near a phase transition can be accurately ascertained.

\subsection{Phase Transitions}

The phenomena which occur near two types of phase transitions will be described here with the purpose to show the power of the method.

\subsubsection{Metal to Superconductor Phase Transitions}

The metal to superconductor transition is studied in the layered cuprate materials, $\mathrm{YBa}_{2} \mathrm{Cu}_{3} \mathrm{O}_{7-\delta}$ and $\mathrm{Nd}\left(\mathrm{Ba}_{0.95} \mathrm{Nd}_{0.05}\right)_{2} \mathrm{Cu}_{3} \mathrm{O}_{7}$ at the $\mathrm{Cu}_{K}, \mathrm{Y}_{\mathrm{K}}, \mathrm{Ba}_{\mathrm{L}}$ and $\mathrm{Nd}_{\mathrm{L}}$ edges versus temperature $\mathrm{T}$.

3.2.1.1 The $\mathrm{Cu}_{K}$ XANES provide an example to show how the changes in symmetry at the transition temperature can be detected. An as grown $\mathrm{YBa}_{2} \mathrm{Cu}_{3} \mathrm{O}_{7-\delta}$ single crystal [5], labeled CT has a thickness $\mathrm{d}_{\mathrm{c}} \sim 22 \mu \mathrm{m}$ determined by Absorbance at the $\mathrm{Cu}_{\mathrm{K}}$, $\mathrm{Ba}_{\mathrm{L} 3,2}$ and $\mathrm{Y}_{\mathrm{K}}$ edges (Figures 5-7). The dipolar edge transitions, $\mathrm{Cu} 1 \mathrm{~s}<->\mathrm{n} \mathrm{p}_{\mathrm{i}}$ are independent of the temperature (Figure 5) at the at a crystal orientation relative to the Xray polarization direction $\boldsymbol{\varepsilon}_{\mathrm{x} \text {-rays }}, \theta=\boldsymbol{\varepsilon}_{\mathrm{x} \text {-rays }} \wedge_{\mathbf{C}}$ when c is the sample crystallographic axis (Figure 3). The transitions' symmetry, in a single crystal, are identified by the orientation dependence of the amplitude versus $\theta$. The baseline corrected raw data (Figure 5a) is manipulated to obtain important information as follows:

$\mu_{A}$ is evaluated (Figure $5 \mathrm{~d}$ ) by normalizing the absorbance A to the zero XAFS amplitude curve, extrapolated to the edge $\mathrm{E}_{0}$ : 


$$
\mu_{\mathrm{A}}=\mathrm{A} / \mathrm{A}_{\mathrm{XAFS}, 0}
$$

$\mu_{\mathrm{AE}}$ evaluates the amplitude of the transitions to finite states by subtracting the transitions to the continuum, relation (6.2) from $\mu_{A}$ (Figure 5g):

$$
\mu_{\mathrm{AE}}=\mu_{\mathrm{A}}-\left\{1 / 2+\Sigma_{\mathrm{i}}\left(\mathrm{x}_{\mathrm{i}} \operatorname{atan}\left(\mathrm{m}\left(\mathrm{E}-\mathrm{E}_{0 \mathrm{i}}\right)\right) / \pi\right\}\right.
$$

where $\mathrm{m}=2 \pi \tau / \mathrm{h} \sim 0.3 / \mathrm{eV}\left(\tau=2.2 * 10^{-16} \mathrm{~s}\right)$ and the mole fractions are $\mathrm{x}_{\mathrm{i}}=1 / 3,2 / 3$ for $\mathrm{Cu}$ in the $\mathrm{CuO}$ chains and in the $\mathrm{CuO}_{2}$ planes respectively. A good fit is obtained from $\mathrm{T}$ $=49$ to $100 \mathrm{~K}$ (Figure $5 \mathrm{~h}$ ) when the data is fitted to:

$$
\mathrm{E}_{0 \mathrm{i}=\text { chains }}-\mathrm{E}_{0 \mathrm{i}=\text { planes }}=6 \mathrm{eV}
$$

in relation (6.2) for the respective valence states. It has been shown for elements with multiple valence, $V$ that the edge position changes at a rate of $\mathrm{dE}_{0} / \mathrm{d} V \approx 5$ to $6 \mathrm{eV}$ [4b,14f], which obtains:

$$
V(\mathrm{Cu} \text { in chains })-V(\mathrm{Cu} \text { in planes }) \approx 1
$$

over the entire temperature interval.

$\mu_{\text {CuEn }}$ is evaluated (Figure 5e) to confirm the dipolar nature of the transitions:

$$
\mu_{\mathrm{CuEn}}=\mu_{\mathrm{CuE}}(\theta) / \cos (\theta)
$$

When it is independent of $\theta$ the final states are assigned to 1 s $<->n p_{x, y}$ transitions. Although the sample geometry prevents obtaining data for $\theta<\pi / 4$, the presence of a transition $1 \mathrm{~s}<->n \mathrm{p}_{\mathrm{z}}$ is identified from $\left(\mu_{\mathrm{Cu}}(\pi / 4)-\mu_{\mathrm{Cu}}(\pi / 2)\right) / \sin (\pi / 4)$ (Figure $\left.5 f\right)$.

$\mathrm{XTDAS}_{\mathrm{Tc}}$ are evaluated to determine if new allowed transitions appear, as a result of changes in the symmetry and density of final states $N\left(E_{E}\right)$ of the material, near a phase transition temperature $\mathrm{T}_{\mathrm{c}}$ (Figures $\left.5 \mathrm{~b}, \mathrm{c}\right)$ :

$$
\mathrm{XTDAS}_{\mathrm{Tc}}=\mathrm{A}\left(\mathrm{T}_{\mathrm{c}}\right)-\mathrm{A}\left(\mathrm{T} \neq \mathrm{T}_{\mathrm{c}}\right) \text {. }
$$


These are two orders of magnitude lower in amplitude, but much broader than the dipolar transitions. HWHH $\sim 10 \mathrm{eV}$ obtain $\tau \sim 6.6 * 10^{-17}$ s. They have been assigned to the quadrupolar terms in relation (6.1), assuming that nd states become available at $\mathrm{T}_{\mathrm{c}}$.

The decrease in the atomic (AT)XAS absorption coefficient, $\mathrm{K}_{\mathrm{Cu}}$ for high photoelectron kinetic energy (Figures $5 \mathrm{a}$ ) at $\mathrm{T}_{\mathrm{c} 1}=93.1$, and $\mathrm{T}_{\mathrm{c} 2}=60 \pm 2 \mathrm{~K}$ is assigned to a line broadening due to fluctuations. If this is due to a decrease in the lifetimes of the final states, we obtain for the crystal CT the same value derived from the XANES quadrupolar transitions line widths (Figure 5b, c):

$$
\tau\left(\mathrm{T}_{\mathrm{c}}\right) \leq 1 / 2 \tau\left(\mathrm{T} \neq \mathrm{T}_{\mathrm{c}}\right) \approx 10^{-17} \mathrm{~s} .
$$

The new clues given by the analysis are an increase in the final density of nd states, and an increase in the fluctuations which give rise to broader line widths, only near $\mathrm{T}_{\mathrm{c}}$.

3.2.1.2. The $B a_{L}$ edge spectra also provide new insight into the phenomena occurring near phase transitions. At the $\mathrm{Ba}_{\mathrm{L} 3,2}$ edges the edge transitions are:

$$
2 \mathrm{p}_{3 / 2,1 / 2}<->\text { nd. }
$$

The XANES and XAFS (Figure 6a) are sharp (with less than $3 \mathrm{eV}$ line widths) at all temperatures at the crystal orientation (Figure 3) $\theta=\pi / 2$. Rotation from $\theta=\pi / 2$ to $\theta=$ $8 \pi / 18$, produces a signal enhancement which increases as the temperature is lowered below $120 \mathrm{~K}$ (Figures 6b,c). The enhancement increases over two orders of magnitude (Figures 6d,e) as the temperature decreases below $\mathrm{T}_{\mathrm{c} 1}$, and an interference pattern (Figure 6f) is observed with a period of $0.67 \mathrm{eV}$ at the $\mathrm{Ba}_{\mathrm{L} 3}$ edge that increases at the $\mathrm{Ba}_{\mathrm{L} 2}$ edge $0.72 \mathrm{eV}$. These phenomena can be qualitatively explained by the propagation of electromagnetic radiation into the crystal by X-ray diffraction by individual planes 
containing the $\mathrm{Ba}$ atoms coupled by a surface plasmon (when this appears at a given temperature $\mathrm{T}<121 \mathrm{~K}$ ) in a way which is similar to surface enhanced Raman scattering [16a]. Near $\lambda=2.36 \AA$ ( $\left(\mathrm{Ba}_{\mathrm{L} 3}\right.$ edge) and $2.20 \AA$ ( $\mathrm{Ba}_{\mathrm{L} 2}$ edge), at $\theta=8 \pi / 18$, there is an enhancement in the Ba planes' diffraction (which satisfy the Bragg condition $S_{\mathrm{hkl}}=2$ $\sin \left(\theta_{\mathrm{hkl}} / \lambda\right)$ due to absorption [15]. The diffracted wave length in the $\mathrm{i}^{\text {th }}$ layer $\lambda_{\mathrm{i}}=\mathrm{E}_{\mathrm{i}} / \mathrm{hc}$ is determined by the index of refraction: $n_{i+1} / n_{i}=\lambda_{i} / \lambda_{i+1}$. The expression for $n=1-\delta-i \beta$ [15a] allows to estimate $\delta /$ layer $\sim 7.7 * 10^{-6}$ for planes containing the $\mathrm{Ba}$ atom. If the interference period $\mathrm{dE}=0.67 \mathrm{eV}$ is produced by an energy and/or phase shift, on flux enhancement by diffraction, this must occur over $17 \sim$ layers or $\sim 21 \mathrm{~nm}$ of sample is much smaller than the sample thickness $d_{c} \sim 22 \mu$ m. This new phenomenom may be associated with the vibrational modes in the lattice that involve the Ba atoms [16]. Recent work [16a] shows that the Raman vibrational modes involving the Ba atoms and the O3A and O3B atoms (Figure 3) soften above $100 \mathrm{~K}$ in the related compound $\mathrm{YBa}_{2} \mathrm{Cu}_{4} \mathrm{O}_{8}$. The phenomenom is not observed at $\mathrm{Cu}_{K}$ edge of $\mathrm{CT}$ near $\mathrm{T}_{c}$ [17] because there is no anomalous Bragg condition, nor at the $\mathrm{Zn}_{\mathrm{K}}$ edge in $\mathrm{YBa}_{2} \mathrm{Cu}_{3-\mathrm{x}} \mathrm{Zn}_{\mathrm{x}} \mathrm{O}_{7-\delta}$ in the anomalous Bragg enhancement of diffraction at room temperature [16b], nor at other edges [16c] where the anomalous Bragg diffraction was measured only at room temperature. At least two conditions must be present to observe the enhancement, the coincidence of absorption with the Bragg condition and the presence of a plasmon [16a]. The Absorbance enhancement factor (Figure 6e):

$$
\begin{gathered}
\varepsilon_{\mathrm{A}}=\mathrm{A}(\mathrm{T}) / \mathrm{A}\left(\mathrm{T}_{\mathrm{ref}}\right)=\varepsilon_{\mathrm{K}, \mathrm{Ba}}\left\{1+\mathrm{XAFS}(\mathrm{T}) / \mathrm{K}_{\mathrm{Ba}}(\mathrm{T})\right\} /\left\{1+\mathrm{XAFS}\left(\mathrm{T}_{\text {ref }}\right) / \mathrm{K}_{\mathrm{Ba}}\left(\mathrm{T}_{\mathrm{ref}}\right)\right\} \\
->\varepsilon_{\mathrm{K}}\left\{1+\Delta_{\mathrm{XAFS}}\right\}
\end{gathered}
$$


has contributions from the atomic absorption coefficient, $\varepsilon_{\mathrm{K} \text {,Вaц3 }}=\mathrm{K}_{\mathrm{BaL} 3}(\mathrm{~T}) / \mathrm{K}_{\mathrm{BaL} 3}\left(\mathrm{~T}_{\text {ref }}\right)$ and since $\mathrm{XAFS}(\mathrm{T})<<\mathrm{K}_{\mathrm{Ba}, \mathrm{L} 3}(\mathrm{~T})$ then $\Delta_{\mathrm{XAFS}} \cong \mathrm{XAFS}(\mathrm{T}) / \mathrm{K}(\mathrm{T})-\mathrm{XAFS}\left(\mathrm{T}_{\mathrm{ref}}\right) / \mathrm{K}\left(\mathrm{T}_{\mathrm{ref}}\right)<<1$. Thus the enhancement is mainly in $\mathrm{K}_{\mathrm{Ba}, \mathrm{L} 3}(\mathrm{~T})$ as $\mathrm{T}<\mathrm{T}_{\mathrm{c}}$, going through maxima versus $\mathrm{E}$ when the anomalous Bragg condition is satisfied (Figure 6e) but the modulation follows the XAFS signal [12]. The Raman studies of Watanabe et al. [16a] indicate that the Ba$\mathrm{O} 3$ and $\mathrm{Ba}-\mathrm{O} 2$ modes soften below $130 \mathrm{~K}$ in $\mathrm{YBa}_{2} \mathrm{Cu}_{4} \mathrm{O}_{8}$, so the modulation most probably arise from corresponding changes in the XAFS.

The weighted $\mathrm{k}^{3}$ XTDAS for CT, at the $\mathrm{Ba}_{\mathrm{L} 3}$ edge (Figure 6h) between $\mathrm{T}_{1}<$ $\mathrm{T}_{\mathrm{c} 2}$, and $\mathrm{T}_{2}>\mathrm{T}_{\mathrm{c} 2} \sim 60 \pm 2 \mathrm{~K}$ (Figure $5 \mathrm{a}$ ) shows a long wave oscillation, which is not present when both $T_{1}, T_{2}>T_{c 2}$ (insert Figure 6h). Complete oscillations are found for the powder sample $\mathrm{Nd}\left(\mathrm{Ba}_{0.95} \mathrm{Nd}_{0.05}\right)_{2} \mathrm{Cu}_{3} \mathrm{O}_{7}$ (Figure 6i). These are attributed to atomic (AT)XAFS observed at $\left(\mathrm{R}_{\text {electron density }}+\Delta\right)<1 \AA$, in the Fourier Transform. These are hard to interpret in condensed phases, because of the scattering from nearby atoms, and features can only be measured in the XAS of gases [11], and in the $\mathrm{Rb}^{+}$vapor power spectrum [11b]. If in a phase transition the only change that occurs is in the electron density near a given site, it may be detected by (AT)XTDAFS for a heavy atom absorber (e.g., Ba, Y). The long wave length oscillations observed versus the photoelectron wave vector $\mathrm{k}$ (Figures 6i) with a period of $\Delta \mathrm{k} \simeq 4.5 \AA^{-1}$ (Figure 6i) do not correspond to a bond change but to a change in electron density near the $\mathrm{Ba}$ atom near $\mathrm{T}_{\mathrm{c}}$ for $\mathrm{Nd}\left(\mathrm{Ba}_{0.95} \mathrm{Nd}_{0.05}\right)_{2} \mathrm{Cu}_{3} \mathrm{O}_{7}$. The advantage of XTDAS here is that the XAFS contributions from all the other bonds were subtracted out, allowing one to identify the bonds and electron density changes at the phase transition. 
3.2.1.3 The orientation dependence at the $\mathrm{Y}_{\mathrm{K}}$ edge confirms the dipolar nature of the edge transitions (Figure 7). Also weak interference fringes are observed at the same orientation as those observed near the Ba edge below $\mathrm{T}_{\mathrm{c} 1}$. The $\mathrm{Y}_{\mathrm{K}}$ edge occurs at $\mathrm{E}_{0, \mathrm{YK}_{\mathrm{K}}} \sim$ $3 \mathrm{E}_{0, \mathrm{Ba} 22}$, and the anomalous Bragg condition would also satisfied for $\mathrm{Y}$ atoms in the $\mathrm{Ba}$ planes (Figure 7b), and the effect is reduced by the fraction of $Y$ impurities. The $Y_{K}$ edge XTDAFS (Figure 7 c-e) identify electron density changes near the $\mathrm{Y}$ atom, versus orientation, below $\mathrm{T}_{\mathrm{c} 1}$. A decrease (negative XTDAFS) in electron density is observed when the polarization $\varepsilon_{\mathrm{X} \text {-rays }}$ is in the crystal ab plane (Figure 7c) while it increases (positive XTDAFS) when the polarization is above the ab plane (Figures 7b,c).

\subsubsection{Paramagnetic Metal to Antiferromagnetic Metal Phase Transitions}

Paramagnetic to antiferromagnetic metal transitions by XAS are investigated for $\mathrm{NiS}_{2-\mathrm{x}} \mathrm{Se}_{\mathrm{x}}$ at the $\mathrm{Ni}_{\mathrm{K}}$ and $\mathrm{Se}_{\mathrm{K}}$ edges versus temperature and composition $\mathrm{x}$. The base line corrected XAS (Figure 8a) show a different versus temperature dependence than for the metal to superconducting phase transition. The $\mathrm{XTDAFS}_{7 \mathrm{~K}}=\mathrm{A}(7 \mathrm{~K})-\mathrm{A}(\mathrm{T})$, for $\mathrm{x}=0.47$ (Figure 8b) [9b, 10b] are different than for $\mathrm{x}=0.6$ (Figure 8d-f) [8] which can be explained by the material phase diagram [1b] obtained from conductivity and magnetic susceptibility data (Figure 8c). From $\mathrm{x}=0.4$ to 0.5 there is a broad transition in the limit of $0 \mathrm{~K}$ from an antiferromagnetic (AF) insulator (I) to an AF metal (M) and the limit shifts to higher values of $x->0.6$ as the temperature in increased. The fraction of Se sites occupied at the onset of the transition, $20 \%$ is at the percolation limit for metallic conduction by the Se atoms in the cubic lattice. The new observations are:

3.2.2.1 The sharp $\mathrm{Se}_{\mathrm{K}}$ edge $\mathrm{XTDAFS}_{7 \mathrm{~K}}$ oscillations observed for $\mathrm{NiS}_{2-\mathrm{x}} \mathrm{Se}_{\mathrm{x}}$ (Figure $8 b, \mathrm{x}=0.47)$ correspond to the Se-Ni bond, $\mathrm{R}_{\mathrm{Se}-\mathrm{Ni}}=2.3 \AA$. The advantage of XTDAFS in 
the study of phase transitions in complicated structures is that only the bond responsible for the transition is selected.

3.2.2.2 When the phase diagram [1b] indicates that an electronic phase transition (Figure 8d) occurs near $36 \mathrm{~K}$, the bond distance $\mathrm{R}_{\mathrm{S}-\mathrm{Se}}$ increases from 3.14 to $3.3 \AA$ near $36 \mathrm{~K}$ (Figure 8c), as determined by XAFS analysis [10b]. If there are no structure changes other than an increase in the Debye-Waller factor for the Ni-Se bond with temperature $(7-37 \mathrm{~K})$, the $\mathrm{XTDAFS}_{7 \mathrm{~K}}$ oscillations represent the change between 7 to 27 $\mathrm{K}$ in the bond vibrations (Figure 8c).

3.2.2.3 At temperatures $\mathrm{T}>37 \mathrm{~K}$ the structure changes, and $\mathrm{XAFS}(\mathrm{T})$ are not in phase with the XAFS(7 K) so the XTDAFS cancel by interference.

3.2.2.4 For $\mathrm{x}=0.6[8]$ the $\mathrm{XTDAFS}_{7 \mathrm{~K}-\mathrm{T}}$ are similar to those for $\mathrm{x}=0.47$, which identifies that the Ni-Se bond is undergoing changes in the Debye-Waller factor as the temperature increases, in the metallic phase (Figure 8d) where the change in slope indicates there is a change in the lifetime of the final states. $\tau_{6 \mathrm{~K}}>\tau_{7 \mathrm{~K}}>\tau_{12 \mathrm{~K}}>\tau_{20 \mathrm{~K}}>\tau_{37 \mathrm{~K}}$ $>\tau_{51 \mathrm{~K}}>\tau_{75 \mathrm{~K}}$. The $\mathrm{XTDAFS}_{7 \mathrm{~K}}$ structure is still observable near $75 \mathrm{~K}$. The phase diagram for $\mathrm{x}=0.6$ (Figure 8d) does indeed show that the metallic state still obtains at $75 \mathrm{~K}$ [1b].

For $x=0.6$ [8], the $\mathrm{XTDAFS}_{5-75 \mathrm{~K}}$ (Figure 8g) indicate a change in the (AT)XAFS due to a decrease in electron density near the Se atom at $75 \mathrm{~K}$ relative to $7 \mathrm{~K}$.

\section{Conclusions:}

4.1 The methods discussed in this work indicate what types of changes may be observed, by the XAS technique of precise measurements of Absorbance A versus temperature, across a phase transition. These are: 
4.1.1 the changes in the relaxation time of the final states, $\tau_{\text {final states }}$ due to fluctuations near a phase transition,

4.1.2 the anomalous Bragg condition coupled to phonon modes XAS enhancement identifies the temperature interval where the phonon modes are active,

4.1.3 the symmetry changes which introduce new allowed transitions to finite states below an element edge, near $T_{c}$ indicate changes of symmetry,

4.1.4 the techniques of $\mathrm{XTDAS}_{\mathrm{T} 1-\mathrm{T} 2}$ and $\mathrm{XTDAFS}_{\mathrm{T} 1-\mathrm{T} 2}$, allows the detection of new transitions, and also precise measurement of the progressive changes in the Debye-Waller factor for a given bond, versus temperature when no other structural changes occur, except in the vibrational modes of a specific bond, which may in turn be responsible for the transition.

4.2 Also it is of some importance to determine the degree of thermodynamic stability [18] for the phenomena observed at a given phase transition as follows:

4.2.1 The interplay of charge transfer with the formation of charge density waves (CDW) and/or spin density waves (SDW) leads to fluctuations, that determines whether a superconducting or an antiferromagnetic state is formed at the metal to nonmetal transition [19]. Understanding these effects can lead to the discovery of useful materials. The Boltzmann probability $\left(\mathrm{e}^{\mathrm{S} / \mathrm{kB}}\right)$ of a thermodynamic state is determined by its entropy $\mathrm{S}$ in units of the Boltzmann constant $\mathrm{k}_{\mathrm{B}}$. The system can be treated thermodynamically as long as its relaxation time $\tau$ is sufficiently long to produce small fluctuations, i.e., when $\Delta \mathrm{S} / \mathrm{k}_{\mathrm{B}}<<1$ at a given temperature $\mathrm{T}[12,18]$. The Uncertainty Principle:

$$
\Delta \mathrm{E} \Delta \mathrm{S} \sim \mathrm{T} \Delta \mathrm{S} \tau \geq \mathrm{h} / 4 \mathrm{p}
$$


where $\Delta \mathrm{E}$ and $\Delta \mathrm{S}$ are the uncertainty in energy and entropy, and $\mathrm{h}$ is Planck's obtains:

$$
\Delta \mathrm{S} / \mathrm{k}_{\mathrm{B}} \geq \mathrm{h} /\left(4 \pi \tau \mathrm{k}_{\mathrm{B}} \mathrm{T}\right) \sim 3.82 * 10^{-12} /\{\tau(\mathrm{s}) \mathrm{T}(\mathrm{K})\} .
$$

Then, as long as $\tau \mathrm{T} \geq 4 \mathrm{ps} \mathrm{K}$, the uncertainty $\Delta \mathrm{S} / \mathrm{k}_{\mathrm{B}}$ is small compared to unity, and the system can be treated thermodynamically. Here relation (7.1) is applied to both antiferromagnetic and superconducting systems $[1,12]$ in order to understand how the displacement in equilibrium to metals, insulators, and antiferromagnets and superconductors works.

4.2.2 Relation (7.1) obtains for cuprates $\Delta \mathrm{S}\left(\mathrm{T}_{\mathrm{C}}\right) / \mathrm{k}_{\mathrm{B}}>>1$ indicating that fluctuations [12,19] are responsible for the transition to superconductivity. The superconducting transition in both single crystal and powder superconducting cuprates is associated with a change in the Ba electron density near $\mathrm{T}_{\mathrm{c}}$ that is preceded by a BaO3A/B bond vibration softening where fluctuations can be studied.

4.2.3The $\mathrm{XTDAFS}_{7 \mathrm{~K}-\mathrm{T}}$ indicate that the Ni-Se bond is involved in the antiferromagnetic/ferromagnetic phase transitions in the Honig--Spałek phase diagram [1b] near $7 \mathrm{~K}$ in $\mathrm{NiS}_{2-\mathrm{x}} \mathrm{Se}_{\mathrm{x}}$ for $\mathrm{x}=0.47$ and 0.6. An increased domain order may be reflected in the longer relaxation time $\tau$ obtained below 7K in relation (7.1) (Figure 8a).

4.2.4 The $\mathrm{XTDAFS}_{75 \mathrm{~K}-7 \mathrm{~K}}$ differentiate between $\mathrm{x}=0.47$ and 0.6 in the paramagnetic-insulating to paramagnetic/antiferromagnetic-metal transition for $\mathrm{NiS}_{2-\mathrm{x}} \mathrm{Se}_{\mathrm{x}}$.

\section{Acknowledgments:}

Work supported by NSF-DMR Grant 9612873 and NSF-INT Grant 9312176 between SJSU and the IRC for Superconductivity Cambridge University for JVA at SJSU and NSF-DMR Grant9612130 for J.M.H at Purdue University. DOE support at SSRL is acknowledged through proposal 2425M. 


\section{References:}

1. (a) N. F. Mott, "Metal to Insulator Transition", Taylor and Francis, 1974, 1990; (b) J.M. Honig and J. Spałek, Chem. Mater, 10, 2810 (1998)

2. P.W. Atkins, "Physical Chemistry", 6th Edition , W.H. Freeman and Co, New York, 1998

3. M. J. Latimer, A. Rompel, J. H. Underwood, V.K. Yachandra and M.P. Klein, Rev. Sci. Instrum. 66, 1843 (1995)

4. J.V. Acrivos, K. Hathaway, J. Reynolds, J. Code, S. Parkin, M.P. Klein, A. Thompson and D. Goodin, Rev. Sci. Instrum. 53, 575 (1982);

5. C.T. Lin, W.Zhou and Y. W. Liang, Physica C, 195291 (1992)

6. J.V. Acrivos, Lei Chen, P. Metcalf, J.M. Honig, R.S. Liu and K.K. Singh, Phys. Rev. $B, \mathbf{5 0}, 13710$ (1994)

7. X. Yao and J.M. Honig, Mater. Res. Bull. 29, 709 (1994)

8. J.V. Acrivos and R. Shaikh, unpublished (2000)

9. (a) L. Nguyen, et al., Am. Phy. Soc. March Meeting, Bull Am Phys. Soc.,43, 345 (1998); (b) T. Norman et al., Am. Phy. Soc. March Meeting, Bull Am Phys. Soc., 43, 871 (1998); (c) T. Norman, L. Nguyen, A. T. Nguyen, C. M. Burch, T. H. Vu, Q. van Le, J. V. Acrivos, "Stanford Synchrotron Radiation Laboratory Activity Report" 2375M, (1997);

10. (a) L. Nguyen, "MS Thesis", SJSU (2000); (b) T. Norman, "M.S. Thesis", SJSU (2000); (c) J.V. Acrivos, Lei Chen and C.M. Burch, Superlattices and Microstructures, 18, 197 (1995) 
11. (a) A.L. Ankudinov and J.J. Rehr, J. Phys. IV France 7, C2- 121 (1997); (b) A. Kodre, I. Arçon and R. Frahm, ibid., C2-195 (1997); (c) Y.A. Babanov, A.V. Ryazhkin and A.F. Sidorenko, ibid, C2-277 (1997)

12. J.V. Acrivos, Solid State Sciences, 2, 807 (2000)

13. C. Brouder, J. Phys.:Condens. Matter 2, 701 (1990)

14.(a) F.K. Richtmyer, S.W. Barnes and E. Ramberg, Phys. Rev. 46, 843 (1934); (b) A. Kodre, I. Arçon and R. Frahm, Physica, C2-195 (1997); (c) Y.A. Babanov, A.V. Ryazhkin and A.F. Sidorenko, ibid, C2-277 (1997); (d) G. Li, F. Bridges, G.S. Brown, Phys. Rev. Lett 68, 1609 (1992); (e) D.H. Templeton, Handbook of Synchrotron Radiation, 3, 201 (1991), eds., G. Brown and D.E. Moncton, Elsevier; (f) B.K. Teo, "EXAFS", Springer-Verlag, Berlin (1985)

15. (a) D.H. Templeton, Handbook of Synchrotron Radiation, 3, 201 (1991), eds., G. Brown and D.E. Moncton, Elsevier; (b) R.S. Howland, T.H. Geballe, S.S. Laderman, A. Fischer-Colbrie, M. Scott, J.M. tarascon, P. Barboux, Phys.Rev., B39, 9017 (1989); (c) M.A. Aranda, D.C. Sinclair, J.P. Attfield, A.P. MacKenzie, Phys. Rev., B51, 12747 (1995)

16. (a) N. Watanabe and N. Koshizuka, Advances in Superconductivity IX, p. 153 , Springer-Verlag, Tokyo (1997); (b) C. Thomsen and M. Cardona, Physical Properties of High Tc Superconductors I, p. 409 (1988), World Scientific, D. M. Ginsberg, ed

17. C. H. Booth, F. Bridges, J.M Boyce, T. Claeson, B.M. Lairson, R. Liang, and D. Bonn, Phys. Rev., B54, 9542 (1996) 
18. (a) L.D. Landau and E.M. Lifshitz, "Statistical Physics", translated by J.B. Sykes and M.J. Kearsley, Pergamon Press NY 1993; (b) P.G. de Gennes, Phys Rev. 118, 141 (1960); (c) C. Castellani, C. Di Castro and M. Grilli, Z. Phys. B 103, 137 (1997) 


\section{List of Figures:}

Figure 1: XAS spectrometer configuration for the measurement in transmission at SSRL, station 2-3.

Figure 2: XAS spectrometer calibration as $A_{v} / A->1$. (a)100 $A_{v} / A$ versus the actual counts measured in the real time clock rtc/ $\mathbf{I}_{\mathbf{0}}$ at the $\mathrm{Cu}_{\mathrm{K}}$ edge. (b) Shift in the value $\mathrm{E}_{0}$ at the $\mathrm{Cu}_{\mathrm{K}}$ edge in a $\mathrm{Cu}$ metal thin film, as $\mathrm{A}_{v} / \mathrm{A}->1$. (c) XAS spectrometer temperature $\mathrm{T}$ measurement: the actual sample $\mathrm{NiS}_{2-\mathrm{x}} \mathrm{Se}_{\mathrm{x}} \mathrm{A}$ versus $\mathrm{T}$, compared with the constancy of the reference A for a Se film. The insert shows the actual temperature $\mathrm{T}$ cycle for the measurment.

Figure 3: Mounted crystal $\mathrm{YBa}_{2} \mathrm{Cu}_{3} \mathrm{O}_{7-\delta}$. Photograph of a crystal (CT) mounted in the Al holder that goes into the cryostat (Figure 1). A lead mask, with a center hole (same shape as the crystal) covers it. A grid with $\pi / 6$ angle marks is used to determines the azimuthal orientation $\phi$. The angle that the crystal c-axis makes with the X-ray polarization vector: $\theta=\mathbf{c}^{\wedge} \boldsymbol{\varepsilon}_{\mathrm{X} \text {-rays }}$ is determined outside the cryostat by a goniometer to \pm 2 DEG.

Figure 4: Calculated atomic absorption coefficient: (a) $K$ versus $m$ and $E-E_{0}$. (b) $K$ versus $E_{F}$ and $E-E_{0}$. (c) $K\left(m=1 \mathrm{eV}^{-1}\right)$ versus $E-E_{0}$. (d) Variance of $K$ versus $m$ and $E-E_{0}$. Figure 5: $\mathrm{Cu}_{\mathrm{K}}$ edge XAS of Single Crystal $\mathrm{YBa}_{2} \mathrm{Cu}_{3} \mathrm{O}_{7-\mathrm{d}}$ (labeled CT) as grown at the IRC for superconductivity, ref. 5. (a) XAS versus T. The constant sample density versus $\mathrm{T}$ is ascertained by $A_{v, \max }=1.8 \mathrm{Ln}(10)$ versus T. (b) $A_{\mathrm{Cu}}(60 \mathrm{~K})-<A_{\mathrm{Cu}}\left(\mathrm{T} \neq \mathrm{T}\right.$ ) $>$. (c) $A_{\mathrm{Cu}}(92$ $\mathrm{K})-<A_{\mathrm{Cu}}\left(\mathrm{T} \neq \mathrm{T}_{\mathrm{c}}\right)>$. (d) $\mu_{\mathrm{Cu}}$ versus $E$ with two inserts: (e) $\mu_{\mathrm{CuEn}}=\mu_{\mathrm{CuE}}(\theta) / \cos (\theta)$ versus $\mathrm{E}$ confirms dipolar nature of edge transitions, and (f) $p_{0}=\left\{\mu_{\mathrm{CuE}}(\pi / 4)-\mu_{\mathrm{CuE}}(0)\right\} / \sin (\pi / 4)$ 
obtains contribution from $1 \mathrm{~s}<->n \mathrm{n}_{\mathrm{z}}$ transition versus $\mathrm{E}$. (g) $\mu_{\mathrm{CuE}}$ versus $\mathrm{E}$ at different $\theta$ gives the dipolar transitions at the edge. (h) $\mu_{\mathrm{CuE}}$ (experimenytal) (48 to $100 \mathrm{~K}$ ) compared to the sum of Lorentzian curves calculated $\mu_{\mathrm{CuE}}$ for $\mathrm{E}_{0} \mathrm{Cu}$ (chains) $-\mathrm{E}_{0} \mathrm{Cu}$ (planes) $=6 \mathrm{eV}$.

Figure 6: $\mathrm{Ba}_{\mathrm{L} 3,2}$ edge $\mathrm{XAS}$ of $\mathrm{YBa}_{2} \mathrm{Cu}_{3} \mathrm{O}_{7-\delta}$ single crystal labeled $\mathrm{CT}$ and $2 \mu \mathrm{m}$ powder $\mathrm{Nd}\left(\mathrm{Ba}_{0.95} \mathrm{Nd}_{0.05}\right)_{2} \mathrm{Cu}_{3} \mathrm{O}_{7}, 1: 5$ weight ratio in $\mathrm{BN}$. (a,b,c) $\mathrm{CT} \mathrm{Ba}_{\mathrm{L} 3}$ edge intensity for $\theta=$ $\pi / 2$ to $8 \pi / 18$ as $\mathrm{T}$ decreases below $\mathrm{T}_{\mathrm{c}}$. (d) $\mathrm{XTDAS}_{121 \mathrm{~K}}$ at $\theta=8 \pi / 18$. The $\mathrm{Ba}_{\mathrm{L} 2}$ $\mathrm{XTDAS}_{121 \mathrm{~K}}$ are multiplied by 5 . A maximum is achieved above $\mathrm{T}_{\mathrm{c} 2}$. (e) $\mathrm{Ba}_{\mathrm{L} 3,2} \mathrm{XAS}$ enhancement $\varepsilon_{\mathrm{Bat} 3,2}$ versus $\mathrm{T}$ at $\theta=8 \pi / 18$ at different temperatures. A maximum is achieved above $\mathrm{T}_{\mathrm{c} 2}$. (f), (g) $A_{\mathrm{Ba}}(\mathrm{L} 3), A_{\mathrm{Ba}}(\mathrm{L} 2)$ enhancement showing interference pattern at $\theta=8 \pi / 18$. (h) $\mathrm{k}^{3} \mathrm{XTDAS}_{\mathrm{T} 1, \mathrm{~T} 2}$ at two $\mathrm{T}$ intervals: $\mathrm{T}_{\mathrm{c} 1}>\mathrm{T}_{1}>\mathrm{T}_{\mathrm{c} 2}>\mathrm{T}_{2}$ and $\mathrm{T}_{\mathrm{c} 1}>\mathrm{T}_{1}, \mathrm{~T}_{2}>$ $\mathrm{T}_{\mathrm{c} 2}$ showing a change in (AT)XAFS occurs below $\mathrm{T}_{\mathrm{c} 2}$ in Figure 5a. (i) $\mathrm{XTDAS}_{\mathrm{Tc} 2}$ for the spectra $\mathrm{Ba}_{\mathrm{L} 3}$ edge XAS averaged over all temperatures 115 to $7 \mathrm{~K}$, for $2 \mu \mathrm{m}$ powder $\mathrm{Nd}\left(\mathrm{Ba}_{0.95} \mathrm{Nd}_{0.05}\right)_{2} \mathrm{Cu}_{3} \mathrm{O}_{7}$. This identifies the second transition at $\mathrm{T}_{\mathrm{c} 2}$ with a change in the electron density near the Ba atom.

Figure 7: $\mathrm{Y}_{\mathrm{K}}$ edge $\mathrm{XAS}$ in $\mathrm{YBa}_{2} \mathrm{Cu}_{3} \mathrm{O}_{7-\delta}$ labeled $\mathrm{CT}$,: (a) $\mu_{\mathrm{YE}}(\theta)$ versus $\theta$, with orientation dependence similar to $\mu_{\mathrm{CuE}}$. (b) $\mu_{\mathrm{YE}}(\pi / 4)-\mu_{\mathrm{YE}}(\theta=\mathrm{n} \pi)$ at $65 \mathrm{~K}$. When $\theta=$ $17 \pi / 36$, the interference fine structure is $\mathrm{dE}_{\mathrm{Y}}=1.27 \mathrm{eV} \sim 2 \mathrm{dE}_{\text {Ba. }}$. Here $\lambda=\lambda_{\text {Ba L2-edge }} / 3 \AA$ indicates that third order diffractions of those near the Ba edge may be responsible for the interference pattern. The absorbers involved, may be those occurring as impurities in the Ba layer. (c), (d), (e) Change in Y AT-XAFS vs $\mathrm{T}$ at different $\theta$ below $\mathrm{T}_{\mathrm{c}}=92 \mathrm{~K}$.

Figure 7: XTdAS for $2 \mu \mathrm{m}$ size powder $\mathrm{NiS}_{2-\mathrm{x}} \mathrm{Se}_{\mathrm{x}}(\mathrm{x}=0.47: \mathrm{m} 3$ cubic lattice $\mathrm{a}=\mathrm{b}=$ $\mathrm{c}=5.753(9) \AA$ in ref. $1 \mathrm{~b})$ diluted in 1 to 5 parts per weight in $\mathrm{BN}$ near the $\mathrm{Se}_{\mathrm{K}}$ edge. The 
spectrometer stability is confirmed by the Se film reference XAS, and the constant sample density by the constant edge $\mathrm{A}_{v}=0.125 \operatorname{Ln}(10)$ versus temperature for all the spectra.

Figure 8: XAS from a $2 \mu \mathrm{m}$ size powdered $\mathrm{NiS}_{2-\mathrm{x}} \mathrm{Se}_{\mathrm{x}} \mathrm{m} 3$ cubic lattice $\mathrm{a}=\mathrm{b}=\mathrm{c}=5.7539 \AA[10 \mathrm{~b}]):(\mathrm{a})(\mathrm{x}=0.47$, diluted in 1 to 5 parts per weight in $\mathrm{BN}$, near the Se-K edge at different temperatures $\mathrm{T}$. (b) $\mathrm{XTDAFS}_{7 \mathrm{~K}}$ versus the inverse photoelectron wave vector $(x=0.47)[10 c]$. (c) Se-S bond distance obtained by XAFS analysis [10b] showing a distinct structural change near $37 \mathrm{~K}$. (d) Phase diagram versus composition [1b]. (e, f) $\mathrm{XTDAFS}_{7 \mathrm{~K}}$ versus the inverse photoelectron wave vector $(\mathrm{x}=0.6)$ [8]. $(\mathrm{g})$ $\mathrm{XTDAFS}_{5 \mathrm{~K}-75 \mathrm{~F}}$ show (AT)XAFS due to a decrease in the electron density near the Se atom at $75 \mathrm{~K}$ relative to $5 \mathrm{~K}$. This was not observed for the $\mathrm{x}=$ 0.47 sample. 